\title{
Evidence for a Concentration Gradient Favoring Outward Movement of Sodium from the Thin Loop of Henle
}

\author{
Paul A. Johnston, Carlos A. Battilana, Frank B. Lacy, and Rex L. Jamison \\ From the Division of Nephrology, Stanford University Medical Center, Stanford, California 94305
}

\begin{abstract}
A B S T RACT Recent models of the urinary concentrating mechanism have postulated that urea in the medullary interstitium creates a transtubular concentration gradient for sodium between fluid at the end of the descending limb of Henle's loop and the medullary interstitium, favoring the passive outward movement of sodium from Henle's thin ascending limb. These experiments were designed to determine whether such a gradient normally exists. Young nondiuretic Munich-Wistar rats were prepared for micropuncture of the exposed left renal papilla. Samples of loop of Henle fluid and vasa recta plasma (assumed to reflect the composition of interstitial fluid) were obtained from adjacent sites. Loop fluid values in 21 comparisons from 18 rats (mean $\pm \mathrm{SE}$ ) were: sodium, $344 \pm 12 \mathrm{meq} / \mathrm{liter}$; potassium, $26 \pm 2$ meq/liter; osmolality, $938 \pm 37 \mathrm{mosmol} / \mathrm{kg} \mathrm{H}_{2} \mathrm{O}$. Vasa recta plasma values (in corresponding units of measurement) were: sodium, $284 \pm 11$; potassium, $34 \pm 2$; osmolality, $935 \pm 34$. Mean values of paired differences (loop fluid minus vasa recta plasma) were: $\Delta$ sodium, $60 \pm 11.1(P<0.001) ; \Delta$ potassium, $-8.0 \pm 2.1 \quad(P$ $<0.001) ; \Delta$ osmolality, $4 \pm 16$ (NS). Corrected for plasma water, the loop fluid minus vasa recta differences (in milliequivalents per kilogram $\mathrm{H}_{2} \mathrm{O}$ ) were: $\Delta$ sodium, $40 \pm 11.4(P<0.005) ; \Delta$ potassium, -9.7 $\pm 1.9(P<0.001)$. We interpret these findings to indicate that in the papilla of nondiuretic rats, a significant difference in sodium concentration exists across the thin loop of Henle favoring outward movement of sodium, which confirms a key requirement of the pas-
\end{abstract}

Portions of this work were presented to the American Society for Clinical Investigation. Johnston, Paul A., Carlos A. Battilana, Frank B. Lacy, and Rex L. Jamison. 1976. Evidence for a concentration gradient favoring outward movement of sodium from the thin loop of Henle in non-diuretic rats. Clin. Res. 34: 468A.

Dr. Johnston is a Fellow of the Bay Area Heart Association. Dr. Battilana is a Fellow of the National Kidney Foundation.

Received for publication 27 April 1976 and in revised form 9 August 1976. sive models. A concentration difference for potassium in the reverse direction was also observed.

\section{INTRODUCTION}

It is generally accepted that a small transtubular difference in osmolality, produced by the reabsorption of $\mathrm{NaCl}$ across the water-impermeable epithelium of the ascending limb, is multiplied by countercurrent flow to establish a progressive osmotic gradient from cortex to papillary tip $(1,2)$. There is strong experimental evidence favoring the active removal of chloride from the thick segment of Henle's ascending loop $(3,4)$ but the mechanism of $\mathrm{NaCl}$ reabsorption in the thin ascending segment remains controversial. While findings obtained from experiments in vivo are consistent with active sodium transport, they do not constitute rigorous proof thereof (5-10), and studies of the thin loop in vitro have failed to demonstrate any active transport process (11).

Two models of the concentrating mechanism have been described which show how $\mathrm{NaCl}$ may be reabsorbed from the thin segment of Henle's loop by passive movement down a concentration gradient $(12,13)$. According to these models, urea in the interstitium of the inner medulla osmotically extracts water from the thin descending limb of Henle's loop, thereby increasing the $\mathrm{NaCl}$ concentration in the tubule fluid to a level higher than that in the interstitium. As fluid enters the thin ascending limb, $\mathrm{NaCl}$ is passively transported (14) into the interstitium down its concentration gradient, diluting the contents of the luminal fluid, and thus establishing the essential transtubular difference in osmolality.

In a previous study from this laboratory (15), we interpreted our findings to indicate that the administration of urea to protein-depleted rats enhanced urinary osmolality by increasing the abstraction of water from the descending limb. The absolute difference in sodium concentration between fluid at the end of the descending limb and vasa recta plasma, 
however, was small and statistically insignificant, although the change in the transtubular concentration difference induced by urea was significant. Subsequently, in the course of experiments performed on normal hydropenic rats for another reason (16), we discovered a transtubular difference in sodium concentration across the end of the descending limb. The purpose of the present experiments was to verify that preliminary observation.

\section{METHODS}

Young Munich-Wistar rats of either sex, weighing 80-110 g, were anesthetized with inactin $(90 \mathrm{mg} / \mathrm{kg}$ body weight) and prepared for micropuncture of the exposed left renal papilla by methods previously described (17). Throughout the study, the animals were infused with $0.9 \%$ saline $(0.02-0.03 \mathrm{ml} / \mathrm{min})$ containing a concentration of inulin sufficient to maintain a plasma level of $80-100 \mathrm{mg} / 100 \mathrm{ml}$.

Fluid was collected near the bend of thin loops of Henle with a pipette having a tip diameter of $7 \mu \mathrm{m}$, for a period of 3-10 min (17). Minimal suction was used during the collection, and no attempt was made to keep the oil drop from moving slowly downstream.

After loop fluid collection, blood from adjacent vasa recta was collected with a pipette having a tip diameter of 9-10 $\mu \mathrm{m}$. In most instances ascending vasa recta (AVR ${ }^{1}$ ) blood was collected. When it was technically impossible to sample nearby AVR, descending vasa recta (DVR), in which the blood flow was deliberately slowed (see below) (7), were punctured. After collection of the sample, the pipette was suspended in the tip down position and the cells allowed to separate from the plasma. Plasma was then expelled from the pipette under oil onto the side of a plastic sampling trough where portions were obtained for analysis of sodium, potassium, inulin, and osmolality.

The following criteria were established at the beginning of the project concerning VR samples to insure that their composition was closely representative of that of the medullary interstitium: (1) The collection must be deemed technically acceptable at the time of puncture: blood flow in the AVR must remain visually unchanged from that before puncture; blood flow upstream in DVR must be slowed to a point that individual erythrocytes can be distinguished to insure osmotic equilibration with the interstitium (7); blood flow must be quickly responsive to changes in pressure in the syringe barrel; the entry of blood into the pipette must be continuous; and no leaks must be present at the puncture site. (2) The inulin concentration in VR plasma samples must not exceed that of systemic plasma by a value which represents $5 \%$ of the inulin concentration in papillary urine. (3) The osmolality of VR samples must not differ from that of adjacent loop fluid by more than $15 \%$.

The first criterion was developed on the basis of experience gained from several years of puncturing VR capillaries. The studies of Jamison et al. (7) and Marsh and Azen (10) suggest that the composition of normally flowing AVR blood more nearly reflects the composition of the surrounding interstitium than that of normally flowing DVR blood, probably owing to the higher velocity of blood flow in the DVR and the fact that the permeability to sodium of the DVR capillary is less than that of the AVR capillary (18). By

\footnotetext{
${ }^{1}$ Abbreviations used in this paper: AVR, ascending vasa recta; DVR, descending vasa recta; LH, loop of Henle near papillary tip; VR, vasa recta.
}

TABLE I

Determination of Right Kidney Function

$\begin{array}{lc}\text { GFR, }{ }^{*} \text { ml } \text { min }^{-1} \text { g kidney } w^{-1} & 1.12 \pm 0.04 \\ \text { U/P inulin } & 252 \pm 23 \\ \text { U/P osmolality } & 5.5 \pm 0.3 \\ \text { FE } \mathrm{H}_{2} \mathrm{O}, \% & 0.4 \pm 0.1 \\ \text { FE Na}, \% & 0.2 \pm 0.1 \\ \text { FE K } & \% \\ \text { FE total solute, \% } & 22 \pm 2 \\ \text { Right kidney wt., } m g & 2.4 \pm 0.2 \\ \end{array}$

All data are means \pm SE.

$\mathrm{n}=18$.

* Abbreviations: FE, fractional excretion, in percent of filtered load; GFR, glomerular filtration rate; U/P, urine-to-systemic plasma concentration ratio.

slowing flow in DVR, however, the osmolality of its plasma increases and is presumed to more nearly reflect the osmolality of the interstitium (7).

The second criterion was developed because of recent findings (19) which we interpreted to indicate that, in our hands, occasional high VR plasma inulin concentrations are the result of contamination of VR samples by fluid from nearby collecting tubule fluid or urine bathing the papilla through which the micropipette must pass to puncture VR. Since the concentration of sodium and potassium in urine is quite different from that in VR plasma, it is essential that VR samples not be significantly contaminated by urine. A VR sample was discarded if the inulin concentration was elevated above systemic plasma by greater than $5 \%$ of adjacent collecting duct fluid, as determined by the following equation:

$$
\left(\mathrm{VR}_{\text {In }}-\mathrm{P}_{\text {In }}\right) / \mathrm{CD}_{\text {In }} \times 100
$$

where $\mathrm{VR}_{\text {In }}, \mathrm{P}_{\mathrm{In}}$ and $\mathrm{CD}_{\mathrm{In}}$ are the concentrations of inulin in VR plasma, systemic plasma, and collecting duct fluid, respectively.

A third criterion was employed to insure further that the composition of VR plasma accurately reflected interstitial composition: any sample of VR plasma differing in total osmolality from fluid in an adjacent loop by more than $15 \%$ was arbitrarily discarded.

A fluid sample was obtained from a collecting duct at the end of each experiment, and analyzed for inulin.

Urine from the right kidney was collected from a bladder catheter during the experiment. Arterial blood was sampled every $30 \mathrm{~min}$.

The concentration of sodium, potassium, and inulin and the osmolality of loop of Henle fluid, vasa recta plasma, urine from the right kidney, and arterial plasma were determined by methods previously described (8).

The difference in electrolyte concentration between loop fluid and vasa recta plasma was analyzed for statistical significance with the Student's $t$ test for paired determinations (20).

\section{RESULTS}

In 18 rats, the mean arterial blood pressure was $92 \pm 2$ (SE) $\mathrm{mm} \mathrm{Hg}$, the hematocrit $40 \pm 1 \%$, the plasma sodium $149 \pm 1$ and plasma potassium $4.4 \pm 0.1 \mathrm{meq} /$ 
TABLE II

Composition of Henle's Loop Fluid and VR Plasma

\begin{tabular}{lcccc}
\hline & $\begin{array}{c}\text { Loop } \\
\text { fluid }\end{array}$ & $\begin{array}{c}\text { VR } \\
\text { plasma }\end{array}$ & Difference & $P$ \\
\hline $\mathrm{Na}^{+}$, meq/liter & $344 \pm 12$ & $284 \pm 11$ & $60 \pm 11.1$ & $<0.001$ \\
$\mathrm{Na}^{+}$, meq/kg $\mathrm{H}_{2} \mathrm{O}$ & $344 \pm 12$ & $304 \pm 12^{*}$ & $40 \pm 11.4$ & $<0.005$ \\
$\mathrm{~K}^{+}$, meq/liter & $26 \pm 2$ & $34 \pm 2$ & $-8.0 \pm 2.1$ & $<0.001$ \\
$\mathrm{~K}^{+}$, meq/kg $\mathrm{H}_{2} \mathrm{O}$ & $26 \pm 2$ & $36 \pm 2^{*}$ & $-9.7 \pm 1.9$ & $<0.001$ \\
Osmolality, mosmol/ & & & & \\
$\quad$ kg $\mathrm{H}_{2} \mathrm{O}$ & $938 \pm 37$ & $936 \pm 34$ & $4 \pm 16$ & $\mathrm{NS}$ \\
$n$ & 21 & 21 & 21 & \\
\hline
\end{tabular}

All data are means \pm SE.

* Assuming a protein concentration of $7 \mathrm{~g} / 100 \mathrm{ml}$ in VR plasma (see text).

NS, not significant.

liter, and the plasma osmolality $315 \pm 2 \mathrm{mosmol} / \mathrm{kg}$ $\mathrm{H}_{2} \mathrm{O}$. Table I presents determinations of the function of the unpunctured right kidney in 18 rats. The rats remained nondiuretic throughout the study as indicated by the mean ratios for urine-to-systemic plasma osmolality and urine-to-systemic plasma inulin.

Table II summarizes the mean osmolality and sodium and potassium concentrations of fluid from loops of Henle and plasma from adjacent VR. 21 paired comparisons were made in 18 rats. There was a significant gradient for sodium from loop of Henle fluid to VR plasma of $60 \pm 11.1 \mathrm{meq} / \mathrm{liter}$. A significant gradient for potassium of $8.0 \pm 2.1 \mathrm{meq} / \mathrm{liter}$ was observed in a direction opposite to that for sodium.

Three corrections of the data were considered: (1) for plasma water, (2) for Gibbs-Donnan equilibrium of cations between VR plasma water and interstitial fluid, and (3) for isosmolality of each paired loop and VR sample.

\section{(1) Plasma water}

We previously found the mean protein concentration to be $7.1 \pm 0.4 \mathrm{~g} / 100 \mathrm{ml}$ in DVR plasma in young Munich-Wistar rats treated the same as the rats in this study, and whose values for osmolality of collecting duct and loop of Henle fluid were comparable to the present values (21). Values for mean protein concentration in AVR (21) and, in a later study (22), of VR at the papillary tip were slightly lower than $7 \mathrm{~g} / 100 \mathrm{ml}$. In correcting the present data for plasma water we used the highest mean value. To estimate the volume of VR plasma water, we therefore substituted the value $7 \mathrm{~g} / 100 \mathrm{ml}$ into the following equation (23):

$$
\begin{gathered}
\mathrm{W}_{\mathrm{s}}=100-\mathrm{S}-\alpha \mathrm{P}_{\mathrm{s}} \\
\left(3 \mathrm{~g} / 100 \mathrm{ml}<\mathrm{P}_{\mathrm{s}}<10 \mathrm{~g} / 100 \mathrm{ml}\right)
\end{gathered}
$$

where $\mathrm{W}_{\mathrm{s}}$ is the volume of water $(\mathrm{ml})$ in $100 \mathrm{ml}$ of plasma, $\mathrm{S}$ is the volume $(\mathrm{ml})$ of nonprotein solids in
$100 \mathrm{ml}$ of plasma (1.5), $\alpha$ is the specific molecular volume of serum protein $(0.745)$ and $P_{s}$ is the protein concentration $(\mathrm{g} / 100 \mathrm{ml})$. This equation, derived from studies of normal human plasma, neglects the effect of high concentration of urea (23). Presumably the effect is small.

When corrected for plasma water, the mean sodium concentration in VR plasma was $304 \pm 12 \mathrm{meq} / \mathrm{kg} \mathrm{H} \mathrm{H}_{2} \mathrm{O}$. As noted in Table II, the mean difference in sodium concentration between loop of Henle fluid and VR plasma water was $40 \pm 11.4 \mathrm{meq} / \mathrm{kg} \mathrm{H}_{2} \mathrm{O}(P<0.005)$. A significant gradient for potassium of $9.7 \pm 1.9 \mathrm{meq} / \mathrm{kg}$ $\mathrm{H}_{2} \mathrm{O}(P<0.001)$ also persisted in a direction opposite to that for sodium.

\section{(2) Gibbs-Donnan equilibrium}

To the extent that the protein concentration of VR plasma exceeds that in the interstititum, the cation concentration in plasma water will be higher than that of interstitial fluid (24). If the protein concentration in medullary interstitial fluid is less than that in VR plasma (and there are reasonable grounds for assuming it is [22]), then the cation concentration in the interstitium is less than that in VR plasma water and the difference in sodium concentration between fluid in Henle's thin limb and the interstitium is greater than that calculated by neglecting the GibbsDonnan equilibrium. Therefore use of VR plasma sodium concentration uncorrected for the GibbsDonnan distribution will underestimate the actual loop fluid-vasa recta plasma (LH-VR) sodium gradient. Since no accurate determination of the interstitial fluid protein concentration could be made, however, we did not attempt to correct for the GibbsDonnan equilibrium. It seems reasonable to assume, however, that the calculated gradient for sodium is a lower limit. Conversely, we may be overestimating the concentration gradient favoring the inward movement of potassium.

\section{(3) Isosmolality}

Whether the osmolality of fluid at the end of the descending limb of Henle's loop and that of fluid in the adjacent interstitium are identical is uncertain. Rarely are samples of fluid from the descending limb and plasma from VR identical in osmolality, but when the collections are performed as described in Methods section, the differences are usually small and not consistently in one direction. It therefore seems reasonable to infer that normally the contents of Henle's descending limb and the medullary interstitium are isosmotic at any given level. Assuming that the osmolality of plasma from DVR (in which blood flow was deliberately slowed) or from AVR is identical to 
TABLE III

Comparison of the Composition of Loop Fluid and VR Plasma According to Capillary Sampled

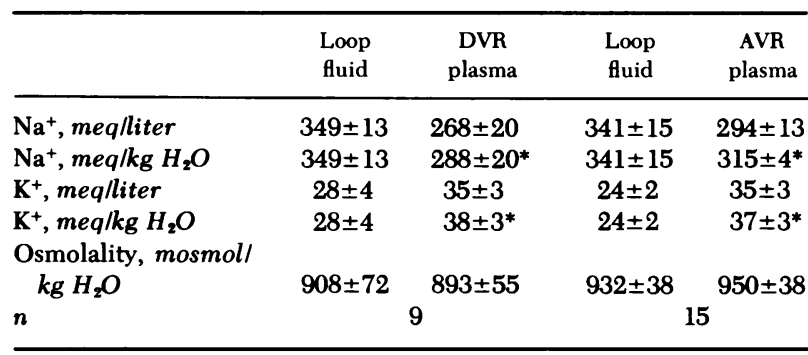

All data are means $\pm \mathrm{SE}$.

*Assuming a protein concentration of $7 \mathrm{~g} / 100 \mathrm{ml}$ in VR plasma (see text).

that of interstitial fluid, the paired electrolyte concentrations in each experiment were corrected for isosmolality ${ }^{2}$ as well as for plasma water. VR plasma sodium and potassium concentrations were $304 \pm 12$ and $36 \pm 2$ $\mathrm{meq} / \mathrm{kg} \mathrm{H}_{2} \mathrm{O}$, respectively. The mean transtubular cation concentration differences (loop fluid minus VR plasma) were: $\Delta$ sodium, $40 \pm 9.9(P<0.001)$ and $\Delta$ potassium, $-10.2 \pm 2.1 \mathrm{meq} / \mathrm{kg} \mathrm{H}_{2} \mathrm{O}(P<0.001)$. Thus the absolute mean values changed little as a result of correction for isosmolality (compare values with those in Table II).

Separate analysis of DVR and AVR samples. As plasma enters the medulla in DVR, water leaves and solute enters the capillary $(22,25)$. If a significant lag in equilibration across the capillary endothelium occursand there is evidence that it does $(7,8)$ - the electrolyte concentration of DVR plasma will be lower than that of adjacent interstitial fluid. Conversely, if a lag in equilibration occurs between the interstitium and AVR plasma, the electrolyte concentration of the plasma will be higher than that of the adjacent interstitium. (In this discussion, the Gibbs-Donnan equilibrium is neglected, but its omission does not invalidate the argument.) A separate analysis of differences between VR plasma and loop fluid according to which capillary, DVR or AVR, was punctured, should set upper and lower bounds, respectively, to the true electrolyte gradient across the loop of Henle. The uncorrected data were therefore divided into two groups, loop fluid and DVR plasma comparisons and loop fluid and AVR plasma comparisons.

Table III summarizes the two groups. Although the osmolality of loop fluid and VR plasma was not significantly different, the sodium gradient from loop of Henle to interstitium, when AVR plasma was used to estimate interstitial fluid composition, was approxi-

${ }^{2}$ The following equation was used to correct for isosmolality between loop of Henle fluid and VR plasma:

$\left(\right.$ Osmolality $_{\mathrm{LH}} /$ Osmolality $\left._{\mathrm{VR}}\right) \times \mathrm{Na}_{\mathrm{VR}}=$ Corrected $\mathrm{Na}_{\mathrm{VR}}$
TABLE IV

Sodium Concentration Differences Between Loop of Henle Fluid and AVR and DVR

$$
\begin{array}{ccc} 
& \text { meqliter } & \text { meq/kg } \mathrm{H}_{2} \mathrm{O} \\
\Delta \mathrm{Na}^{+},(\mathrm{LH}-\mathrm{DVR}) & 81 \pm 19.4 & 61 \pm 20.6 \\
(n=9) & (P<0.001) & (P<0.02) \\
\begin{array}{c}
\Delta \mathrm{Na}^{+},(\mathrm{LH}-\mathrm{AVR}) \\
(n=15)
\end{array} & 47 \pm 10.6 & 26 \pm 10.8 \\
& (P<0.001) & (P<0.05)
\end{array}
$$

All data are means \pm SE.

* Corrected for plasma water using a protein concentration of $7 \mathrm{~g} / 100 \mathrm{ml}$ (see text).

mately one-half that observed when DVR plasma was used (Table IV). Both sodium gradients, (LH-DVR) $=81 \pm 19.4 \mathrm{meq} /$ liter and $($ LH-AVR $)=47 \pm 10.6 \mathrm{meq} /$ liter, were significantly different from zero $(P<0.001)$. Fig. 1 depicts sodium concentration in AVR and DVR plasma versus that in paired loop fluid samples.

When VR plasma was corrected for plasma water, the mean differences were lower but still statistically significant (Table IV). Assuming isosmolality between loop fluid and VR plasma, the (LH-DVR) sodium gradient was $60 \pm 16 \mathrm{meq} / \mathrm{kg} \mathrm{H}_{2} \mathrm{O}(P<0.01)$, and the (LH-AVR) sodium gradient was $33 \pm 10.0 \mathrm{meq} / \mathrm{kg} \mathrm{H}_{2} \mathrm{O}$ $(P<0.01)$.

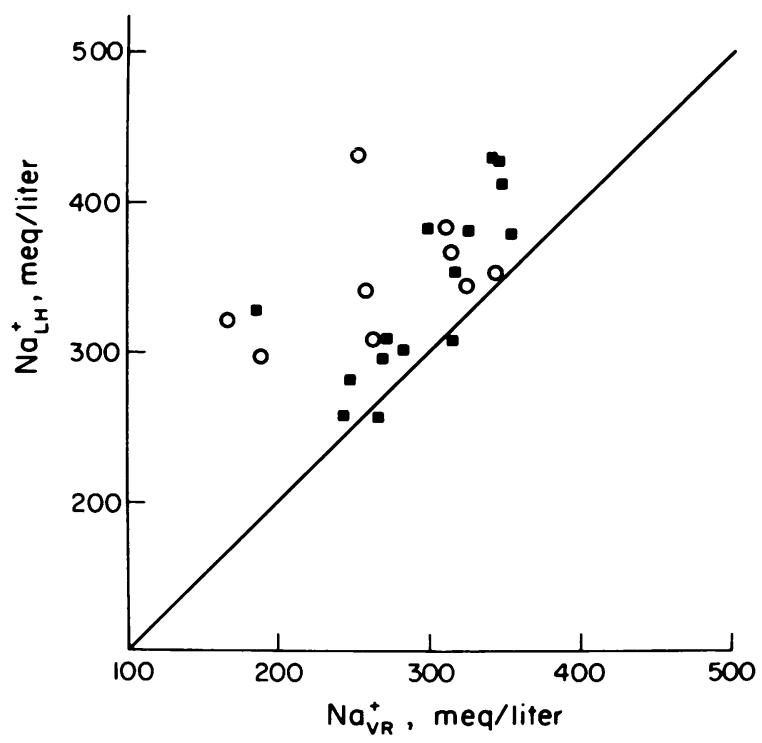

Figure 1 Sodium concentration in loop of Henle fluid $\left(\mathrm{Na}^{+} \mathrm{LH}\right)$ versus sodium concentration in vasa recta plasma $\left(\mathrm{Na}^{+}{ }_{\mathrm{VR}}\right)$, uncorrected for plasma water. Solid squares represent AVR samples $(n=15)$ and open circles represent DVR samples $(n=9)$. Mean $\Delta \mathrm{Na}^{+}$, (LH-DVR), $=81 \pm 19.4 \mathrm{meq} / \mathrm{liter}$ $(P<0.001, n=9)$. Mean $\Delta \mathrm{Na}^{+},(\mathrm{LH}-\mathrm{AVR}),=47 \pm 10.6 \mathrm{meq} /$ liter $(P<0.001, n=15)$. Line is the line of identity. 
The (LH-DVR) potassium gradient, corrected for plasma water, was $-10.1 \pm 4.5(0.05<P<0.06)$, and the (LH-AVR) potassium gradient was $-11.5 \pm 1.9 \mathrm{meq} / \mathrm{kg}$ $\mathrm{H}_{2} \mathrm{O} \quad(P<0.001)$. When corrected for isosmolality between loop of Henle fluid and VR plasma as well as for plasma water, the (LH-DVR) gradient for potassium was $-11.3 \pm 4.9(P<0.05)$, and the $(\mathrm{LH}-\mathrm{AVR})$ potassium gradient was $-12.2 \pm 1.8 \mathrm{meq} / \mathrm{kg} \mathrm{H}_{2} \mathrm{O}(P$ $<0.001)$.

\section{DISCUSSION}

The results indicate a significant difference in sodium concentration across the end of Henle's descending limb favoring the passive outward movement of sodium. The conclusion holds for the raw data, for sodium concentrations corrected for plasma water (Table II) and for separate analyses of (LH-DVR) and (LH-AVR) sodium gradients (Tables III and IV). The minimum sodium gradient in the present experiments lies between 26 and $61 \mathrm{meq} / \mathrm{kg} \mathrm{H}_{2} \mathrm{O}$ (Table IV).

A concentration difference for potassium in the reverse direction was also observed, in agreement with our previous findings (16). We have previously discussed the significance of a gradient favoring transtubular entry of potassium into the descending limb (16). The fact that the potassium gradient was in the opposite direction to that for sodium lends credence to the authenticity of both gradients.

A description of forces influencing the transmembrane movement of an ion is incomplete without knowledge of the transmembrane electrical potential difference, which was not determined in these experiments. In previous studies of the descending limb in vivo $(5,6)$ and in vitro $(26)$, the transtubular potential difference was not significantly different from zero. Thus the difference in sodium concentration between fluid at the end of the thin descending limb and the adjacent interstitium is unlikely to be accounted for by an electrical potential difference. Whether a favorable electrochemical gradient for sodium persists in the thin ascending limb is uncertain. Studies of the hamster by Windhager (5) and by Marsh and Solomon (6) demonstrated a transmembrane potential difference between luminal fluid and interstitium in the thin ascending limb of $10 \mathrm{mV}$, lumen negative. Employing newer techniques, Marsh and Martin (27) have recently found in the same species a lower potential difference, between 1.5 and $2 \mathrm{mV}$, lumen positive, in accord with electrical measurements in the isolated thin ascending limb of the rabbit (11). If these latter findings pertain to the rat, the electrochemical gradient favors passive movement of sodium out of the thin ascending limb.

The findings of an outward transtubule sodium con- centration gradient at the end of the descending limb confirms for the first time a key prediction of the passive models of the urinary concentrating mechanism $(12,13)$. There is general agreement that $\mathrm{NaCl}$ is reabsorbed by the thin ascending limb through a water permeable epithelium; uncertainty, however, exists whether this is an active or passive transport mechanism (5-11).

The models of Stephenson (13) and Kokko and Rector (12) have shown how urea reabsorbed from the collecting tubule and trapped in the medullary interstitium can act osmotically to extract water from the solute-impermeable thin descending limb. As a consequence, the concentration of $\mathrm{NaCl}$ in fluid in the descending limb rises above that in the surrounding interstitium. The concentration of urea, in contrast, remains relatively low in the tubule fluid. The stage is now set for the essential dilution of the contents of the thin ascending limb by outward diffusion of $\mathrm{NaCl}$ through its water-impermeable epithelium. Among the requirements for confirmation of these models are (1) a water permeable, relatively soluteimpermeable descending limb; (2) a NaCl-permeable, water-impermeable ascending limb; (3) the extraction of water from the descending limb by urea; (4) a transtubular difference in $\mathrm{NaCl}$ concentration favoring the outward movement of $\mathrm{NaCl}$ from the thin loop: (5) a low urea concentration in fluid entering the thin ascending limb (a requirement of the completely passive model); and (6) enough urea reabsorbed from the collecting tubule to depress medullary interstitial sodium concentration sufficiently to drive sodium reabsorption in the thin ascending limb.

The first and second requirements have been established for the rabbit thin descending and ascending limb in vitro $(11,26)$, although solute permeabilities of the descending and ascending thin segments in the rat in vitro (28) differ significantly from those of the rabbit and are less easy to reconcile with the passive reabsorptive mechanism $(12,13)$. The third requirement was demonstrated in protein-deficient rats given urea (15). The present paper confirms the fourth prediction. It should be noted that Imbert and de Rouffignac (29) also found a statistically significant outward gradient for sodium at the end of the descending limb in urea-loaded but not in sodium chlorideloaded psammomys; however, the latter group elaborated the more concentrated urine.

The fifth and sixth requirements listed above have not been fulfilled. The concentration of urea in fluid entering the thin ascending limb is probably too high in protein deficient rats given urea (15) and in the normal rats in the present experiments. We estimated the urea concentration of loop fluid by subtracting from the total osmolality the sum of $\mathrm{Na}$ and $\mathrm{K}$ concen- 
trations times their respective osmotic coefficients (30), a method which yields a reasonably close estimate, as determined directly (31). Calculated in this fashion, the mean urea concentration in loop fluid was $254 \pm 30$ mosM, which agrees closely with the mean urea concentration determined directly in loop fluid in an earlier study of normal Sprague Dawley rats, $287 \pm 32 \mathrm{mM}(31)$. This value is probably too high to be consistent with a completely passive model (as discussed previously [15, 31]). Regarding the sixth condition, Stephenson et al. (32) have calculated the amount of urea entering the system necessary to drive $\mathrm{NaCl}$ from the thin ascending limb. Their results suggest that an active solute pump in the thin loop of Henle is probably still necessary. Recently, Marsh and Azen (10) reported results in the hamster consistent with an active sodium reabsorptive mechanism which, they calculated, accounts for approximately half the total transtubular flux of $\mathrm{NaCl}$ from the thin ascending limb.

In summary, the findings in this study confirm a key requirement of the passive urinary concentrating models. Whether the proposed passive mechanism is sufficient to obviate the need for an active transport mechanism in the thin ascending limb remains open to question.

\section{ACKNOWLEDGMENTS}

The authors are grateful to Ms. Mary Fisher and Mr. Steven Pottier for their technical assistance, to Ms. Helen Ramey and Ms. Cassie Laffoon for their secretarial assistance, to Dr. Channing Robertson and Mr. Gene Gussis for helpful discussions, and to Dr. Roy Maffly and Dr. Michael Weiner for criticizing the manuscript.

This study was supported by Research grants from the National Institutes of Health (AM 18077 and 5 ROI HL 4945) and by a grant-in-aid from the American Heart Association (72821) with funds contributed in part by the Bay Area Heart Association.

\section{REFERENCES}

1. Kuhn, W., and K. Ryffel. 1942. Herstellung konzentrierter Lösungen aus verdünnten durch blosse Membranwirkung. Ein Modellversuch zur Funktion der Niere. Hoppe-Seyler's Z. Physiol. Chem. 276: 145-178.

2. Wirz, H., B. Hargitay, and W. Kuhn. 1951. Lokalisation des Konzentrierungsprozesses in der Niere durch direkte Kryoskopie. Helv. Physiol. Pharmacol. Acta. 9: 196-207.

3. Burg, M. B., and N. Green. 1973. Function of the thick ascending limb of Henle's loop. Am. J. Physiol. 224: $659-668$.

4. Rocha, A. S., and J. P. Kokko. 1973. Sodium chloride and water transport in the medullary thick ascending limb of Henle. Evidence for active chloride transport. J. Clin. Invest. 52: 612-623.

5. Windhager, E. E. 1964. Electrophysiological study of the renal papilla of golden hamsters. Am. J. Physiol. 206: 694-700.

6. Marsh, D. J., and S. Solomon. 1965. Analysis of elec- trolyte movement in thin Henle's loops of hamster papilla. Am. J. Physiol. 208: 1119-1128.

7. Jamison, R. L., C. M. Bennett, and R. W. Berliner. 1967. Countercurrent multiplication by the thin loops of Henle. Am. J. Physiol. 212: 357-366.

8. Jamison, R. L. 1968. Micropuncture study of segments of thin loop of Henle in the rat. Am. J. Physiol. 215: 236-242.

9. Marsh, D. J. 1970. Solute and water flows in thin limbs of Henle's loop in the hamster kidney. Am. J. Physiol. 218: 824-831.

10. Marsh, D. J., and S. P. Azen. 1975. Mechanisms of $\mathrm{NaCl}$ reabsorption by hamster thin ascending limbs of Henle's loop. Am. J. Physiol. 228: 71-79.

11. Imai, M., and J. P. Kokko. 1974. Sodium chloride, urea and water transport in the thin ascending limb of Henle. Generation of osmotic gradients by passive diffusion of solutes. J. Clin. Invest. 53: 393-402.

12. Kokko, J. P., and F. C. Rector, Jr. 1972. Countercurrent multiplication system without active transport in inner medulla. Kidney Int. 2: 214-223.

13. Stephenson, J. L. 1972. Concentration of urine in a central core model of the renal counterflow system. Kidney Int. 2: 85-94.

14. Imai, M., and J. P. Kokko. 1976. Mechanism of sodium and chloride transport in thin ascending limb of Henle. J. Clin. Invest. 58: 1054-1060.

15. Pennell, J. P., V. Sanjana, N. R. Frey, and R. L. Jamison. 1975. The effect of urea infusion on the urinary concentrating mechanism in protein-depleted rats. J. Clin. Invest. 55: 399-409.

16. Jamison, R. L., F. B. Lacy, J. P. Pennell, and V. M. Sanjana. 1976. Potassium secretion by the descending limb or pars recta of the juxtamedullary nephron in vivo. Kidney Int. 9: 323-332.

17. Jamison, R. L. 1970. Micropuncture study of superficial and juxtamedullary nephrons in the rat. Am. J. Physiol. 218: 46-55.

18. Marsh, D. J., and L. A. Segel. 1971. Analysis of countercurrent diffusion exchange in blood vessels of the renal medulla. Am. J. Physiol. 221: 817-828.

19. Jamison, R. L., P. A. Johnston, F. B. Lacy, and C. R. Robertson. 1976. The source of inulin in plasma from vasa recta capillaries of the renal medulla in vivo. Clin Res. 24: 162A. (Abstr.)

20. Snedecor, G. W., and W. G. Cochran. 1967. Statistical Methods. Iowa State University Press. Ames, Iowa. 6th edition. 95.

21. Sanjana, V. M., P. A. Johnston, W. M. Deen, C. R. Robertson, B. M. Brenner, and R. L. Jamison. 1975. Hydraulic and oncotic pressure measurements in inner medulla of mammalian kidney. Am. J. Physiol. 228: 1921-1926.

22. Sanjana, V. M., P. A. Johnston, C. R. Robertson, and R. L. Jamison. 1976. An examination of transcapillary water flux in the renal inner medulla. Am. J. Physiol. 231: 313-318.

23. Eisenman, A. S., L. B. MacKenzie, and J. P. Peters. 1936. Protein and water of serum and cells of human blood, with a note on the measurement of red blood cell volume. J. Biol. Chem. 116: 33-45.

24. Donnan, F. G. 1924. The theory of membrane equilibria Chem. Rev. 1: 73-90.

25. Gottschalk, C. W., W. E. Lassiter, and M. Mylle. 1962. Studies of the composition of vasa recta plasma in the hamster kidney. Excerpta Med. Int. Congr. Ser. 47: 375-376. 
26. Kokko, J. P. 1970. Sodium chloride and water transport in the descending limb of Henle. J. Clin. Invest. 49: 1838-1846.

27. Marsh, D. J., and C. M. Martin. 1975. Origin of electrical pd's in hamster thin ascending limbs of Henle's loop. Physiologist. 18: 306. (Abstr.)

28. Morgan, T., and R. W. Berliner. 1968. Permeability of the loop of Henle, vasa recta and collecting duct to water, urea and sodium Am. J. Physiol. 215: 108-115.

29. Imbert, M., and C. de Rouffignac. 1976. Role of sodium and urea in the renal concentrating mechanism in
Psammomys obesus. Pflugers Arch. Eur. J. Physiol. 36: $107-114$.

30. Jamison, R. L., J. Buerkert, and F. Lacy. 1973. A micropuncture study of Henle's thin loop in Brattleboro rats. Am. J. Physiol. 224: 180-185.

31. Pennell, J. P., F. B. Lacy, and R. L. Jamison. 1974. An in vivo study of the concentrating process in the descending limb of Henle's loop. Kidney Int. 5: 337-347.

32. Stephenson, J. L., R. P. Tewarson, and R. Mejia. 1974. Quantitative analysis of mass and energy balance in nonideal models of the renal counterflow system. Proc. Natl. Acad. Sci. U.S.A. 71: 1618-1622. 